\title{
Variable Renewable Generation Can Provide Balancing Control to the Electric Power System
}

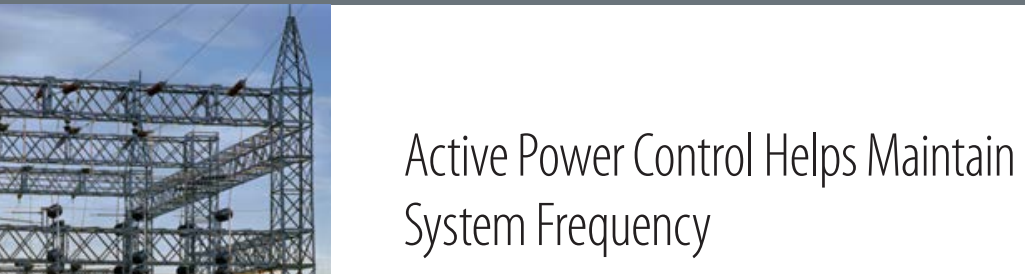

As wind and solar plants become more common in the electric power system, they may be called on to provide grid support services to help maintain system reliability. For example, through the use of inertial response, primary frequency response, and automatic generation control (also called secondary frequency response), wind power can provide assistance in balancing the generation and load on the system. These active power (i.e., real power) control services have the potential to assist the electric power system in times of disturbances and during normal conditions while also potentially providing economic value to consumers and variable renewable generation owners.

\section{Benefits of Active Power Controls}

\section{Inertial Response}

Inertial response is the immediate response to a power disturbance that causes a frequency change, such as the loss of a large generator or a large loss of load. Inertial response is important because it reduces the rate of change of frequency after a disturbance, which can lead to avoidance of underfrequency load shedding or worse issues, including blackouts. Conventional synchronous generators provide inertial response naturally from stored energy in the rotating mass of their turbines.

Most modern, large-scale wind turbines and solar arrays connect to the grid via power electronics-based converters, which isolate the wind and solar generation from grid frequency and enable advanced control functions. Wind turbines can provide an inertial response similar to that of conventional generators by using energy stored in the rotating blades or capturing more energy from converters (Muljadi et al. 2012, Aho et al. 2012). The controls on the power electronics-based converters sense the frequency drop and then determine the appropriate increase in 1 power output. Although wind plants are not widely required to provide inertial response, some plants in Quebec do so. Unlike wind turbines, solar energy systems do not have rotating masses, so they require auxiliary energy to provide a similar response.

\section{Primary Frequency Response}

Primary frequency response (also called frequency responsive reserve and governor droop service) follows inertial response. It is the action by turbine governor controls to change output to balance generation and load and ensure system frequency returns to a stable level following a disturbance. If the frequency deviates too far from its nominal set point (which, in North America, is $60 \mathrm{~Hz}$ ), the reliability of the grid is threatened, underfrequency load shedding relays can trigger involuntary load tripping, and equipment can be harmed. In recent years, many grid operators have seen declines in the primary frequency response available because of the changing ways in which generation owners operate their generating units. Some of these changes may be caused by a lack of financial incentives (Ela et al. 2012). Therefore, the need for primary frequency response in power systems is growing.

When equipped with governor-like controls, wind generating plants can contribute to grid frequency through torque or pitch control. Solar plants can provide this entirely through electronic controls. Wind and solar plants respond best to grid frequency increases, which require a drop in power generation. They can provide primary frequency response to frequency drops, which require a power increase, only when they are operating below maximum output levels. Such curtailment of energy production could have a significant economic impact on a wind or solar plant. Although primary frequency response from wind and solar plants is not widely required, some wind plants in Texas do provide frequency response as a result of recent requirements in the Electric Reliability Council of Texas.

\section{Automatic Generation Control}

Automatic generation control is used to help continuously balance the system, maintain a constant frequency, and eliminate area control error. 


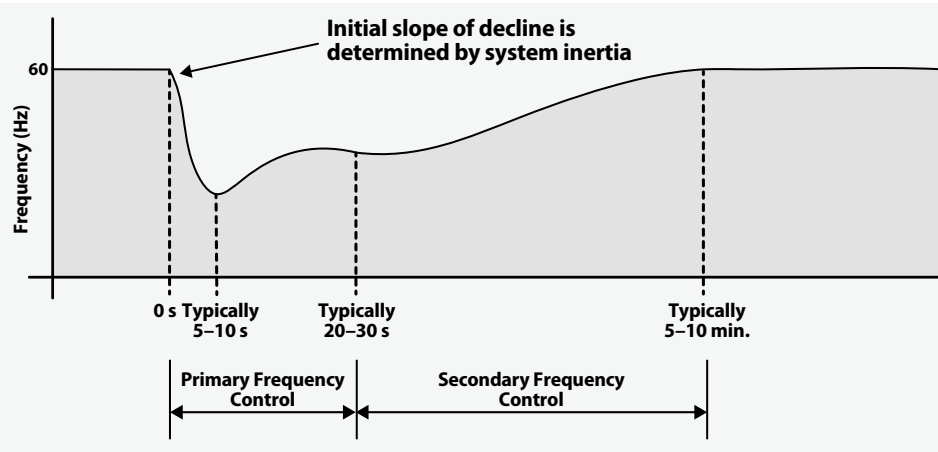

Figure 1. When a disturbance occurs, the frequency of the electric power system deviates from its scheduled level. The frequency must be stabilized and returned to its scheduled level to avoid further reliability issues.

Generators that provide regulation reserve increase or decrease output to meet the constantly changing load, thereby maintaining balance between load and generation on the system and acceptable frequency levels. They do so by responding to automatic generation control signals from a system operator every four to six seconds to determine how much to increase or decrease output. Wind generators are capable of responding to automatic generation control signals to provide regulation service, although they do not typically do so today. In the same way that wind turbines can provide primary frequency response, their blades can be pitched to rapidly increase or decrease output. However, to be able to increase output, they must be scheduled below maximum power output.

To date, the primary growth in solar energy penetration has been on the distribution grid. As solar energy penetration increases on the transmission grid, the ability of solar plants to provide regulation could become more important.

\section{Barriers to Active Power Controls}

Active power controls are not widely used today by wind and solar generators because economic barriers - including upfront equipment costs, lost opportunity costs, and potential to increase loading impacts on the turbine components - discourage their use. Renewable generation operators are not able to justify such costs unless they are compensated for providing these services or are required to do so. In addition, wind and solar generators must operate below full generation output to provide certain balancing services. This has economic consequences. The cost for renewables to provide support services is the lost opportunity cost of generating energy that could be sold into market.

Renewable generators have higher opportunity costs than conventional generators that save on fuel costs by not providing power. Thus, wind and solar generators require greater compensation to provide grid support services because otherwise they could provide power to the system from a free fuel supply — the wind or sun.
In addition, some manufacturers and owners/operators are concerned that providing these services might increase loading on components. For example, very fast changes in wind turbine output power can excite mechanical resonances in the drivetrain. However, initial research has shown that the design of the active power control controller can limit these effects through trade-offs with the aggressiveness of response. Further, when the turbine curtails power to provide reserves for this control, many component loads are actually reduced.

Although wind and other forms of variable generation are not providing these services widely today, there may be a greater need for them to do so in the future as higher penetrations of wind and solar energy are added to the grid.

\section{Associated Publications}

Aho, J.; Buckspan, A.; Laks, J.; Fleming, P.; Jeong, Y.; Dunne, F.; Churchfield, M.; Pao, L.; Johnson, K. (March 2012). "Tutorial of Wind Turbine Control for Supporting Grid Frequency Through Active Power Control." Preprint. Prepared for the American Control Conference, June 27-29, 2012. NREL/CP-5000-54605. Golden, C0: National Renewable Energy Laboratory, 14 pp. Accessed April 2013: www.nrel.gov/docs/fy120sti/54605.pdf.

Ela, E.; Tuohy, A.; Milligan, M.; Kirby, B.; Brooks, D. (2012). "Alternative Approaches for Incentivizing the Frequency Responsive Reserve Ancillary Service." Electricity Journal (25:4); pp. 88-102. Accessed April 2013: http:// dx.doi.org/10.1016/j.tej.2012.04.015.

Muljadi, E.; Gevorgian, V.; Singh, M.; Santoso, S. (2012). "Understanding Inertial and Frequency Response of Wind Power Plants." 2012 IEEE Power Electronics and Machines in Wind Applications (PEMWA) Proceedings; July 16-18, 2012, Denver, Colorado. Piscataway, NJ: Institute of Electrical and Electronics Engineers; 8 pp. Accessed April 2013: http://dx.doi. org/10.1109/PEMWA.2012.6316361.

\section{More Information}

Erik Ela, 303-384-7089, erik.ela@nrel.gov

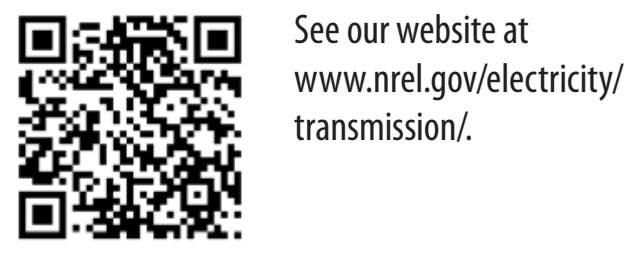

Front page photography (from top): Photo by Warren Gretz, NREL 10924; Photo by Warren Gretz, NREL 10926; Photo from Meet Minneapolis 1, NREL 18700; Photo from Native Energy, Inc, NREL 17591
NREL is a national laboratory of the U.S. Department of Energy, Office of Energy Efficiency and Renewable Energy, operated by the Alliance for Sustainable Energy, LLC.

NREL/FS-5500-57820 • September 2013 